\title{
Idiopathic uveal effusion syndrome
}

INSERM

\section{Source}

INSERM. (1999). Orphanet: an online rare disease and orphan drug data base. Idiopathic uveal effusion syndrome. ORPHA:209956

Idiopathic uveal effusion syndrome is a rare acquired eye disease characterized by uni- or bilateral abnormal fluid accumulation within the suprachoroidal space, resulting in internal choroidal elevation, in the absence of any known cause, such as decreased intraocular tension, intraocular tumor, intraocular inflammation or nanophtalmos. Patients typically present a protracted, relapsing-remitting course of visual acuity loss and fundus examination shows annular celio-choroidal detachment and shifting, serous retinal detachment. 